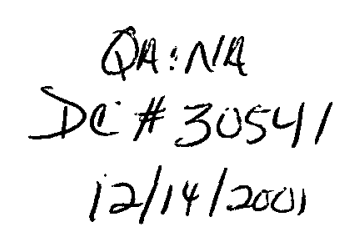

\title{
Corrosion Tests of LWR Fuels - Nuclide Release
}

Patricia A. Finn, Yifen Tsai, and James C. Cunnane

MOL. 20020304.0038 Chemical Technology Division, Argonne National Laboratory 9700 S. Cass Ave, Argonne, IL 60439

\begin{abstract}
Two BWR fuels [64 and $71(\mathrm{MWd}) / \mathrm{kgU}]$, one of which contained $2 \% \mathrm{Gd}$, and two PWR fuels [30 and $45(\mathrm{MWd}) / \mathrm{kgU}$ ], are tested by dripping groundwater on the fuels under oxidizing and hydrologically unsaturated conditions for times ranging from 2.4 to $8.2 \mathrm{yr}$ at $90^{\circ} \mathrm{C}$. The ${ }^{99} \mathrm{Tc}$, ${ }^{129} \mathrm{I},{ }^{137} \mathrm{Cs}$, ${ }^{97} \mathrm{Mo}$, and ${ }^{90} \mathrm{Sr}$ releases are presented to show the effects of long reaction times and of gadolinium on nuclide release. This investigation showed that the five nuclides at long reaction times have similar fractional release rates and that the presence of $2 \%$ Gd reduced the ${ }^{99} \mathrm{Tc}$ cumulative release fraction by about an order of magnitude over that of a fuel with a similar burnup.
\end{abstract}

\section{INTRODUCTION}

A potential site for the U.S. high-level waste repository is in the hydrologically unsaturated volcanic tuff beds at Yucca Mountain, Nevada. To define the source term, the releas $\varepsilon$ behavior of different types of spent fuels under hydrologically unsaturated and oxidizing conditions is needed. For over eight years, PWR fuels with burnups of 30 and $45 \mathrm{MWd} / \mathrm{kgU}$ have been tested under hydrologically unsaturated and oxidizing conditions. Both fuels oxidized and formed alteration phases in less than two years; the phase composition depends on the presence of large amounts of silicate in the groundwater.

To examine possible effects of burnable poisons on nuclide release behavior, two BWR fuels, one containing Gd, were placed under test conditions in late 1998. The radionuclide release data for the first $2.4 \mathrm{yr}$ of reaction of the two fuels is summarized to show differences due to the presence of Gd. Of particular interest are the release behaviors of ${ }^{99} \mathrm{Tc}$ and ${ }^{129} \mathrm{I}$, which are the primary contributors to the dose rate at the Yucca Mountain site boundary for storage times up to $40,000 \mathrm{yr}$, and ${ }^{90} \mathrm{Sr}$, which "monitors" the corrosion of the fuel matrix [1].

\section{EXPERIMENTAL DETAILS}

The PWR fuel with a nominal burnup of $30(\mathrm{MWd}) / \mathrm{kg} \mathrm{U}$ and a fission gas-release of $0.25 \%$ is designated ATM-103 [2]. The PWR fuel with a nominal burnup of $45(\mathrm{MWd}) / \mathrm{kg} \mathrm{U}$ and a fission gas-release of $11 \%$ is designated ATM-106 [3]. The BWR fuel with a burnup of 71 $(\mathrm{MWd}) / \mathrm{kg} \mathrm{U}$ and a fission gas-release of $4.4 \%$ is designated ATM-109A; the BWR fuel with a burnup of $64(\mathrm{MWd}) / \mathrm{kg} \mathrm{U}$, a fission gas-release of $3.5 \%$, and a $2 \% \mathrm{Gd}$ content as $\mathrm{Gd}_{2} \mathrm{O}_{3}$ is designated ATM-109C [4]. 
The test configuration is designed to expose an 8-g fuel sample, which is in the form of fragments that are contained in a Zircaloy holder, to humid air and to a twice-weekly injection of simulated groundwater ("EJ-13"). Details of the test configuration are described elsewhere [5].

To produce EJ-13, water from well J-13 near Yucca Mountain, which has a chemistry representative of the saturated zone below Yucca Mountain, Nevada, is conditioned for eighty days at $90^{\circ} \mathrm{C}$ with crushed core samples of Topopah Spring tuff. The resulting EJ-13 has a pH of 8.4 to 8.6 .

Prior to use, the fuel fragments are dry-sieved on a 20 -mesh sieve $(864 \mu \mathrm{m})$ to remove fines. After sieving, the fuel fragments larger than $864 \mu \mathrm{m}$ are randomly batched into 8-g samples without further processing. Over $99.9 \mathrm{wt} \%$ of the ATM-103, $99 \mathrm{wt} \%$ of the ATM-106, and 82 wt $\%$ of the ATM-109A and ATM-109C were larger than $864 \mu \mathrm{m}$.

The fuel fragments are placed in a Zircaloy-4 holder having a retainer with $10-\mu \mathrm{m}$-diameter holes at its base, except at the 7.7 and $8.2 \mathrm{yr}$ test intervals, when a gold retainer with $200-\mu \mathrm{m}$ diameter holes is used. The fuel holders are housed in type-304L stainless steel vessels. At the start of each test interval, the vessel contains approximately $5 \mathrm{~mL}$ of EJ-13. Every 3 to 4 days, approximately $0.75 \mathrm{~mL}$ of EJ-13 is injected onto the fuel and $0.75 \mathrm{~mL}$ of air. At six-month intervals, the tests are interrupted to remove the leachate. The test vessel is cooled and opened, and the fuel holder is removed from the vessel. The reacted fuel is examined visually and photographed to qualitatively determine the degree of corrosion and look for evidence of alteration phase formation. The fuel holder is then placed in a clean vessel and the test is resumed.

The leachate is removed from the used vessel and the interior of the vessel is acid-stripped to collect nuclides fixed on the walls. Aliquots of the leachate and the acid-strip solution are analyzed by high-resolution gamma spectroscopy to determine ${ }^{137} \mathrm{Cs}$ and by inductively coupled plasma-mass spectroscopy (ICP-MS) to determine ${ }^{99} \mathrm{Tc},{ }^{90} \mathrm{Sr},{ }^{129} \mathrm{I},{ }^{157} \mathrm{Gd}$, and ${ }^{97} \mathrm{Mo}$. The analytical accuracy is estimated to be \pm 20 to $\pm 50 \%$ depending on the nuclide.

Note the following: A nuclide that is entrained by fluid from the fuel holder is defined as being released. The release includes the nuclides in the leachate solution, in colloids suspended in the leachate, and fixed on the vessel interior surfaces; the latter are recovered through an acid strip of the vessel interior. Radionuclides that form alteration phases on the fuel fragments or are sorbed by fuel fragments, alteration phases, or the fuel holder are not included in the total release. The release of each nuclide is normalized to the nuclide content in a fuel sample. The latter is obtained from ORIGEN code calculations for ATM-103 and from analyses of samples similar to those under test for ATM-109A and ATM-109C. The release fraction, $R$, is

$$
\mathrm{R}=\frac{\text { ( } \mathrm{g} \text { nuclide in the leachate }+\mathrm{g} \text { nuclide in the acid-strip) }}{\text { (g nuclide/g fuel })(\mathrm{g} \text { sample })}
$$

The cumulative fraction is the sum of the nuclide release in sequential test intervals. The release rate is the release fraction $\mathrm{R}$ divided by the duration in days of a test interval. 


\section{DISCUSSION}

\section{${ }^{99} \mathrm{Tc},{ }^{129} \mathrm{I},{ }^{137} \mathrm{Cs},{ }^{97} \mathrm{Mo}$, and ${ }^{90} \mathrm{Sr}$ Release in ATM-103 and ATM-106 Tests}

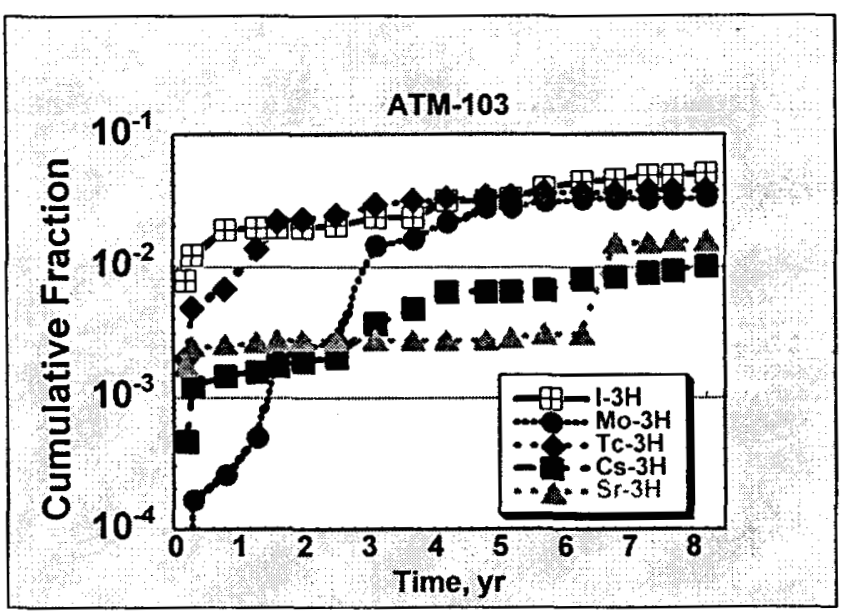

Figure 1. The ATM-103 ${ }^{129} \mathrm{I},{ }^{97} \mathrm{Mo},{ }^{99} \mathrm{Tc},{ }^{137} \mathrm{Cs}$, and ${ }^{90} \mathrm{Sr}$ cumulative release fractions

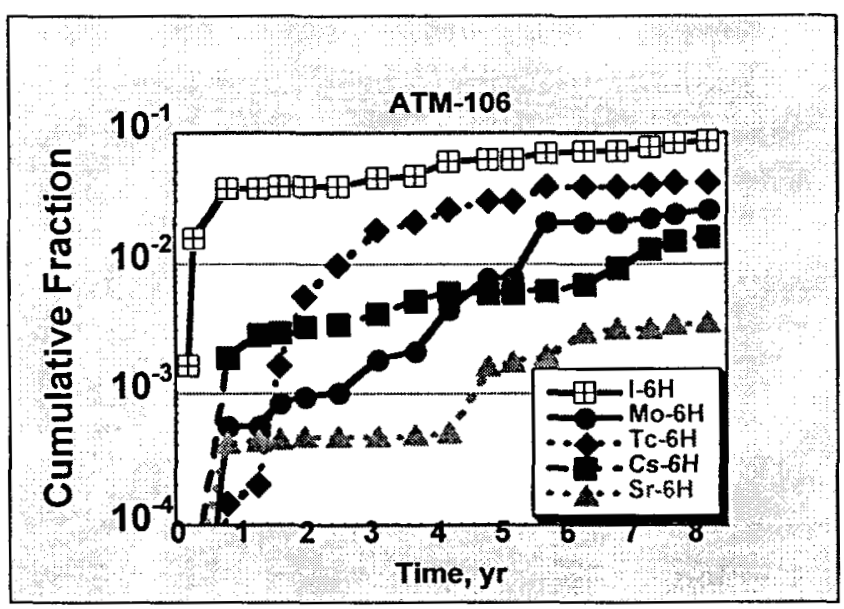

Figure 2. The ATM-106 ${ }^{129} \mathrm{I},{ }^{97} \mathrm{Mo},{ }^{99} \mathrm{Tc},{ }^{137} \mathrm{Cs}$, and ${ }^{90} \mathrm{Sr}$ cumulative release fractions

Figures 1 and 2 summarize the cumulative release fractions of ${ }^{129} \mathrm{I},{ }^{97} \mathrm{Mo},{ }^{99} \mathrm{Tc},{ }^{137} \mathrm{Cs}$, and ${ }^{90} \mathrm{Sr}$ over 8.2 years of reaction for the ATM-103 and ATM-106 tests, respectively. For the two PWR fuels, a general corrosion reaction occurs at the fuel surface [6]. As the fuel reacts and dissolves, over $95 \%$ of the uranium is precipitated as uranyl alteration phases on the fuel surface. Nuclides, which are soluble under unsaturated and oxidizing conditions, are released to the leachate. As the reaction progresses, the contribution of the matrix to nuclide release is expected to dominate, whereas at early reaction times, the contribution from the grain boundaries to nuclide release may dominate. 
A steady increase in the cumulative fraction is seen for most nuclides after four years of reaction. To evaluate the nuclide release rate at long reaction times, a linear least squares fit was done for each nuclide in figures 1 and 2 for the period between 6.2 and 8.2 years. The slope of each fit, in units of mass fraction per year, and the fitting parameter $\mathrm{R}^{2}$, are summarized in table I.

Table I. ATM-103 and ATM-106 release rates for 6.2-8.2 yr. Slopes derived from linear least squares fit of the cumulative release fraction as a function of time.

\begin{tabular}{|c|c|c|c|c|}
\hline Nuclide & $\begin{array}{c}\mathbf{A T M}-103 \\
\text { (fraction/yr } \\
\text { ) }\end{array}$ & $\mathbf{R}^{\mathbf{2}}$ & $\begin{array}{c}\mathbf{A T M}-106 \\
\text { (fraction/yr } \\
\text { ) }\end{array}$ & $\mathbf{R}^{\mathbf{2}}$ \\
\hline${ }^{129} \mathrm{I}$ & 0.0034 & 0.93 & 0.0082 & 0.92 \\
\hline${ }^{99} \mathrm{Tc}$ & 0.0010 & 0.91 & 0.0019 & 0.95 \\
\hline${ }^{97} \mathrm{Mo}$ & 0.0007 & 0.91 & 0.0026 & 0.89 \\
\hline${ }^{137} \mathrm{Cs}$ & 0.0009 & 0.98 & 0.0050 & 0.97 \\
\hline${ }^{90} \mathrm{Sr}$ & $0.0003^{\mathrm{a}}$ & 0.97 & 0.0003 & 0.96 \\
\hline
\end{tabular}

${ }^{\mathrm{a}}$ For the period between 6.8 to $8.2 \mathrm{yr}$.

The rates of release of the different nuclides vary within a factor of 10 for ATM-103 and within a factor of 30 for ATM-106. For a given nuclide, the rates of release vary within a factor of two to five. There is less variation in the rate of release of a given nuclide for two different PWR fuels than in the rate of release of several nuclides of a given fuel.

Note the similar fractional release rates for ${ }^{99} \mathrm{Tc}$ and ${ }^{97} \mathrm{Mo}$, which are consistent with their release being from corroded epsilon phase particles in the fuel matrix. After more than eight years of reaction the fractional release rates of ${ }^{129} \mathrm{I},{ }^{137} \mathrm{Cs}$, and ${ }^{90} \mathrm{Sr}$ are in the order ${ }^{129} \mathrm{I}>{ }^{137} \mathrm{Cs}>{ }^{90} \mathrm{Sr}$, which suggests that either there is preferential release of ${ }^{129} \mathrm{I}$ for more than eight years or that there is retention of some of the ${ }^{137} \mathrm{Cs}$ and the ${ }^{90} \mathrm{Sr}$ in alteration phases. Despite the noted differences in the nuclide release rates, the trend in the long-term release rates of the five nuclides suggests that matrix corrosion is becoming ever more important in controlling nuclide release rates.

\section{Gadolinium's effect on nuclide release}

The cumulative release fractions of ${ }^{137} \mathrm{Cs},{ }^{90} \mathrm{Sr},{ }^{99} \mathrm{Tc},{ }^{97} \mathrm{Mo}$, and ${ }^{129} \mathrm{I}$ during the first $2.4 \mathrm{yr}$ of reaction are shown in figures 3 and 4 for ATM-109A and ATM-109C, respectively. The ${ }^{129} \mathrm{I}$ and ${ }^{90} \mathrm{Sr}$ cumulative fractions are similar in magnitude for both fuels, (i.e. their release does not appear to be affected when Gd is present). In contrast, the ATM-109C ${ }^{137} \mathrm{Cs}$ cumulative fraction is ten times larger than that of ATM-109A; however, most of the difference is due to a very large ${ }^{137} \mathrm{Cs}$ release for the ATM-109C fuel at the first test interval. The two nuclides that appear to be affected at each test interval by the presence of Gd are ${ }^{97} \mathrm{Mo}$ and ${ }^{99} \mathrm{Tc}$. After $2.4 \mathrm{yr}$, the ATM$109 \mathrm{~A}{ }^{97} \mathrm{Mo}$ and ${ }^{99} \mathrm{Tc}$ cumulative release fractions are over an order of magnitude larger than the 
corresponding ATM-109C cumulative release fractions.

As seen in figure 5, the ATM-103, ATM-106, and ATM-109A ${ }^{99}$ Tc cumulative release fractions are similar in magnitude, but all three are at least an order of magnitude larger at $2.4 \mathrm{yr}$ than the cumulative release fraction of the ATM-109C fuel, which contains Gd. In effect, a

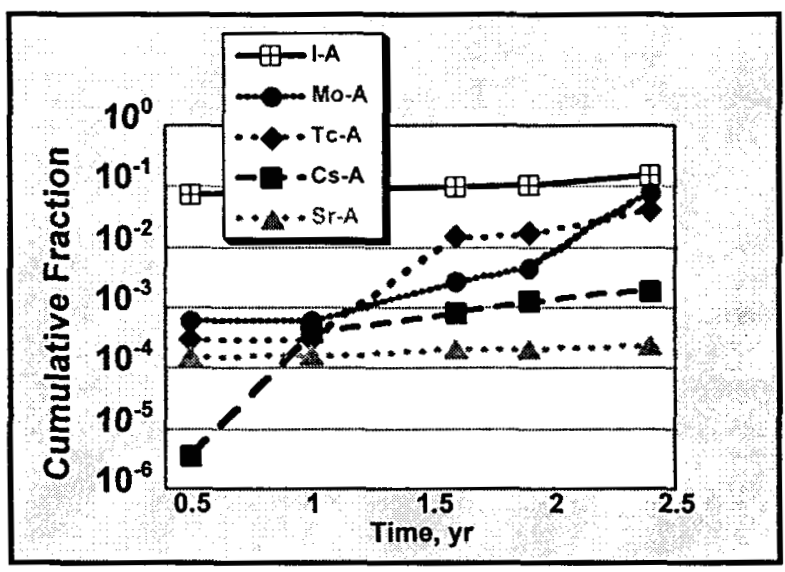

Figure 3. The ATM-109A ${ }^{129} \mathrm{I},{ }^{97} \mathrm{Mo},{ }^{99} \mathrm{Tc},{ }^{137} \mathrm{Cs}$, and ${ }^{90} \mathrm{Sr}$ cumulative release fractions

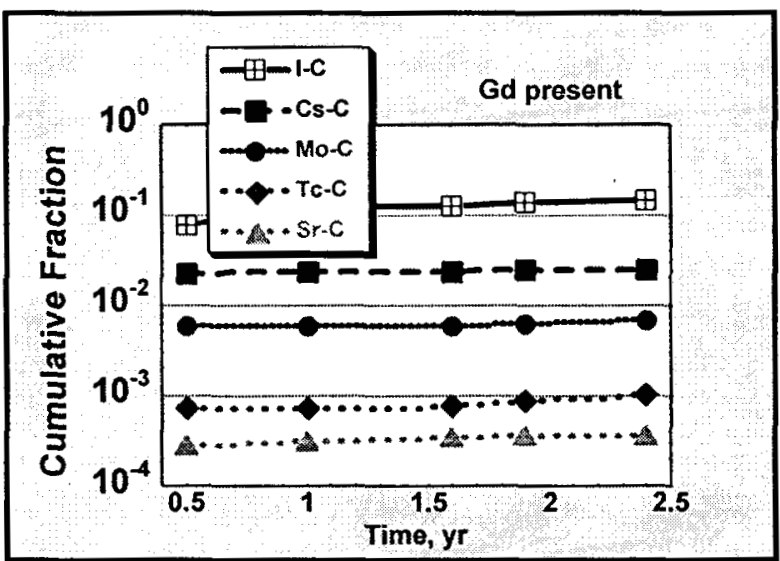

Figure 4. The ATM-109C ${ }^{129} \mathrm{I},{ }^{97} \mathrm{Mo},{ }^{99} \mathrm{Tc},{ }^{137} \mathrm{Cs}$, and ${ }^{90} \mathrm{Sr}$ cumulative release fractions 


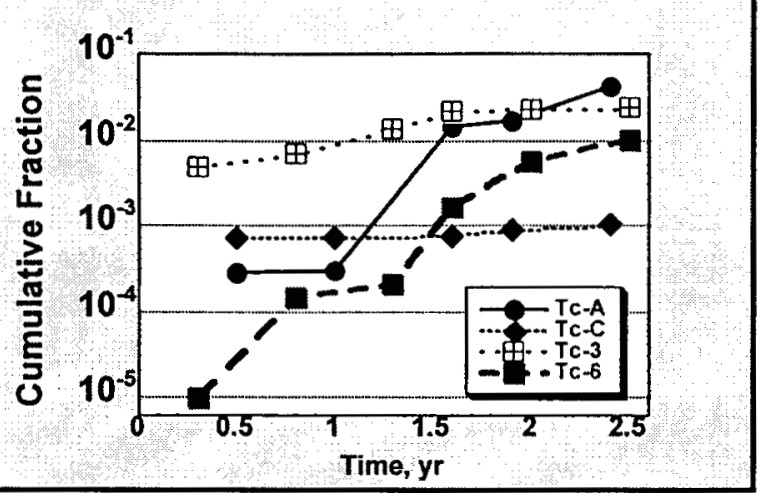

Figure 5. The ATM-109A, ATM-109C, ATM-103, and ATM-106 ${ }^{99} \mathrm{Tc}$ cumulative release fractions

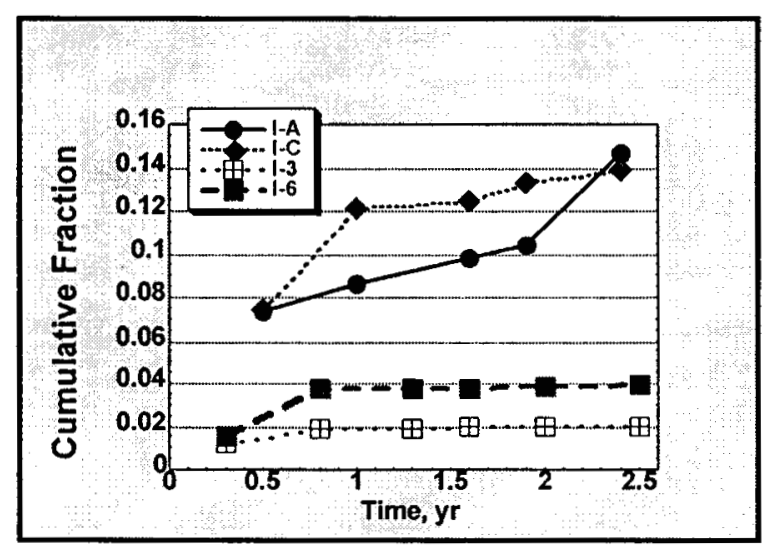

Figure 6. The ATM-109A, ATM-109C, ATM-103, and ATM-106 ${ }^{129}$ I cumulative release fractions

significant reduction in the ${ }^{99} \mathrm{Tc}$ release is found in the presence of Gd.

Figure 6 shows that the ${ }^{129}$ I cumulative release fractions of both ATM-109 fuels, which have burnups of 64 and $71(\mathrm{MWd}) / \mathrm{kgU}$, are similar. Both ATM-109 ${ }^{129}$ I cumulative release fractions are also ten times larger than the ${ }^{129} \mathrm{I}$ cumulative release fractions of the lower burnup ATM-103 $(30(\mathrm{MWd}) / \mathrm{kgU})$ and ATM-106 (45 (MWd)/kgU) fuels at $2.4 \mathrm{yr}$. The larger ATM-109 ${ }^{129} \mathrm{I}$ cumulative release fractions compared to the smaller ATM-103 and ATM-106 ${ }^{129}$ I cumulative release fractions suggest that a larger fraction of the ${ }^{129}$ I may be available for release from the gap and/or grain boundary regions of the ATM-109 fuels.

Post-irradiation examination of irradiated urania-gadolinia [7] showed no fuel restructuring, but rods with $3.4 \%$ fission gas release had more interconnected porosity than those with $1.5 \%$ fission gas release. Thus, there is a potential pathway along the interconnected porosity for water to react with the urania-gadolinia fuel. The Gd release is below ICP-MS detection limits in all but the first test interval for the ATM-109C fuel, which is consistent with the retention of Gd. 
Although the cumulative release fraction data suggest that the presence of $\mathrm{Gd}$ may limit ${ }^{99} \mathrm{Tc}$ release, its presence has a limited effect, if any, on ${ }^{129}$ I release.

Long-term data are needed before the nuclide release fractions can be interpreted in terms of the possible effects of $\mathrm{Gd}$ on the rate of fuel matrix corrosion, grain boundary corrosion, or retention of radionuclides in alteration phases. Resolution of the cause of the lower ${ }^{99} \mathrm{Tc}$ release is important because ${ }^{99} \mathrm{Tc}$ is the main contributor to the dose rate for the resident population at the boundary of the potential Yucca Mountain repository at storage times of less than 40,000 years.

\section{CONCLUSIONS}

The study has shown that the trend in the long-term release rates of ${ }^{129} \mathrm{I},{ }^{97} \mathrm{Mo},{ }^{99} \mathrm{Tc},{ }^{137} \mathrm{Cs}$, and ${ }^{90} \mathrm{Sr}$ for the PWR fuels is consistent with matrix corrosion becoming ever more important in controlling nuclide release rates. There is less variation in the rate of release of a given nuclide for two different PWR fuels than in the rate of release of several nuclides of a given fuel. After more than eight years of reaction the fractional release rates of ${ }^{129} \mathrm{I},{ }^{137} \mathrm{Cs}$, and ${ }^{90} \mathrm{Sr}$ are in the order ${ }^{129} \mathrm{I}>{ }^{137} \mathrm{Cs}>{ }^{90} \mathrm{Sr}$, which suggests that either there is preferential release of ${ }^{129} \mathrm{I}$ for more than eight years or that there is retention of some of the ${ }^{137} \mathrm{Cs}$ and the ${ }^{90} \mathrm{Sr}$ in alteration phases. For the BWR fuels, the presence of $2 \% \mathrm{Gd}$ reduces the ${ }^{99} \mathrm{Tc}$ cumulative release fraction by over an order of magnitude compared to the ${ }^{99} \mathrm{Tc}$ release of a fuel without $\mathrm{Gd}$ but with a similar burnup. The BWR fuels, which have a high burnup [64 and $71(\mathrm{MWd}) / \mathrm{kgU}]$, have ten times larger ${ }^{129}$ I release fractions than the ${ }^{129} \mathrm{I}$ release fractions for lower burnup PWR fuels [ 30 and $45(\mathrm{MWd}) / \mathrm{kgU}$ ].

\section{ACKNOWLEDGEMENTS}

The authors thank Stephen F. Wolf for the gamma analyses. The work is supported by the Yucca Mountain Site Characterization Project (YMP) and by the U.S. Department of Energy, under contract W-31-109-ENG-38.

\section{REFERENCES}

1. R. S. Forsyth, L. O Werme, "Spent Fuel Corrosion and Dissolution," J. Nucl. Mat. 190, 3-19 (1992).

2. R. J. Guenther et al., Characterization of Spent Fuel Approved Testing Material - ATM-103, Pacific Northwest Laboratory Report PNL-5109-103 (1988).

3. R. J. Guenther et al., Characterization of Spent Fuel Approved Testing Material - ATM-103, Pacific Northwest Laboratory Report PNL-5109-106 (1988).

4. S. Vaidyanathan et al., "High Burnup BWR Fuel Pellet Performance," Proc. 1997 Intl. Topical Meeting on LWR Fuel Performance 471-477 (1997).

5. P. A. Finn et al., "Colloidal Products and Actinide Species in Leachate from Spent Nuclear Fuel," Radiochimica Acta 66/67, 189-195 (1994).

6. P. A. Finn, R. J. Finch, E. C. Buck, J. K. Bates, "Corrosion Mechanisms of Spent Fuel under 
Oxidizing Conditions," MRS Symp. Proc. 506, 123 (1998).

7. L. W. Newman, Qualification of the B\&W Mark B Fuel Assembly for High Burnup and Development of an Advanced Design Incorporating Urania-Gadolinia, Babcock and Wilcox Report DOE/ET/34212-57 (1991). 